ORIGINAL PROF-2223

\title{
HOSPITAL WASTE MANAGEMENT;
}

\section{Practices in different hospitals of Distt. Peshawar}

\author{
Dr. Raheelah Amin, Dr. Rubina Gul, Miss Amina Mehrab
}

ABSTRACT... Introduction: Hospital waste is a special type of waste which carries high potential of infection and injury. Objectives: This study was conducted to examine Medical Waste Management Practices in different hospitals of Peshawar. Methodology: Simple observational, cross-sectional study. was conducted with a case study approach. Aug-Sep 2011, with selection of 15 hospitals. The data was collected through a pre-designed questionnaire with a checklist. Results: The study showed that $80 \%$ of the hospital personnel knew hospital waste and its management. There was waste management plan present in $30 \%$ of hospitals. Although hospitals did not quantified waste amounts but on average the amount of waste generated daily was $0.5-1 \mathrm{~kg} / \mathrm{bed} / \mathrm{day}$. Segregation into risk and non risk waste was done in $93.3 \%$ of hospitals. For non risk waste, disposal through Municipal Corporation was conducted in $86.67 \%$ of the hospitals, while in $13.3 \%$, it was burnt. For risk waste, either it was buried or burnt. Proper incineration was carried out in only $33.3 \%$ of the hospitals. Discussion: Hospital waste generation, segregation, collection, transportation \& disposal practices were not in accordance with standard guidelines. The average waste generation in most of the hospitals was almost equivalent to other under developed countries but less than that of developed countries. Conclusions: The hospital waste in the majority of hospitals of Peshawar was mismanaged. No proper hospital waste management plan existed except at few hospitals.

Keywords: Medical Waste, Medical Waste Disposal, Infectious Waste Disposal, Pathological Waste Disposal, Waste Management,

Article Citation

Amin R, Gul R, Mehrab A. Hospital waste management; practices in different hospitals of Distt. Peshawar. Professional Med J 2013;20(6): 988-994.

\section{INTRODUCTION}

Hospital waste is "Any waste which is generated in the diagnosis, treatment or immunization of human beings or animals or in research" in a hospital." "Hospital waste is a special type of waste produced in small quantities carrying a high potential of infection and injury" ${ }^{2}$. There are serious health effects from public health standpoint if hospital waste is not handled properly.

Hospital waste management means "the management of waste produced by hospitals using techniques that will check the spread of diseases through hospital waste" ${ }^{3}$.

Hospital waste consists of both risk waste and non risk waste. Generally, risk waste includes infectious waste, pathological, pharmaceutical, sharps, chemicals, geno-toxic and radioactive wastes. Non-risk waste includes garbage and general day to day waste produced by food stuff leftovers and their packaging ${ }^{4}$.
The developed countries have properly organized infrastructure of hospital waste disposal. A properly trained team is responsible for handling various operational procedures related to waste disposal like segregation, internal transportation, and final disposal.

In developing countries, however situation is not good. There is lack of awareness regarding segregation, collection, storage and transportation and disposal procedures $^{5}$.

Medical waste management has not received much attention in developing countries. Segregation into risk and non risk waste is usually not performed. Workers have little awareness of hazards associated, and disposal techniques are poor ${ }^{6}$. There is also lack of awareness at health policy and law levels ${ }^{7}$.

In case of cyto-toxic drugs, special care is needed during disposal, as contamination of handlers is easy, which can lead to ingestion and absorption causing 
serious health effects. It is needed to adequately educate them and to provide safety equipments ${ }^{8}$.

To achieve sustainable waste disposal system, the three R's- "Reduce, Reuse and Recycle" are generally used. They offer a simple guideline of the types of action to be taken." They are in general order of priority and also called the waste "ministry hierarchy", .

Each hospital should prepare its own health management plan in accordance with national and international guidelines, specific to its unique requirements ${ }^{11}$. It should be ensured that risks from hospital wastes to individuals and environment are minimized to certain extent ${ }^{12}$.

The proper management of health-care waste depends on various factors like proper planning, funding, administration and commitment at policy level. If they are implemented properly, they can lead better effects for both individuals and environment ${ }^{13}$.

Proper waste management can significantly lower the infectious disease burden especially Hep B, C and AIDS, which spreads through I/ $\mathrm{V}$ route.

This study was conducted to examine medical waste management practices in different hospitals of Distt. Peshawar.

\section{METHODOLOGY}

Study Design

Simple Observational, Cross-sectional study design (with case study approach)

\section{Time \& Place}

In Distt. Peshawar from Sep-Oct, 2011 in secondary and tertiary care hospitals of Distt. Peshawar.

\section{Sample Size}

A total of 15 hospitals were selected by convenient sampling. Both tertiary \& secondary care hospitals were included. Personnel involved in waste management were interviewed.

\section{Data Collection Tool}

Structured Questionnaire with check list.

\section{Data Analysis}

Microsoft Excel sheet was used for graphs \& tables.

\section{RESULTS}

A total of 15 hospitals were visited. Regarding awareness, $80 \%$ of the hospital personnel interviewed knew hospital waste management and also considered it important. In $73.3 \%$ of the hospitals, the waste management staff had undergone a training program for hospital waste management. In $60 \%$ of the waste management teams, the members were trained for emergency conditions within the hospital while in $40 \%$ they were not. $66.67 \%$ of the workers thought that safe disposal and segregation of the health care waste was an important issue. A hospital waste management team was present in majority of the health care facilities with 15-21 members present in $33 \%$ of the hospitals. Meetings of the waste management team were conducted twice a month in $6.66 \%$ of the hospitals to revise the waste management policies and update them according to

The health workers handling the transport, segregation and disposal of waste in most of the hospitals i.e. $26.67 \%$ were provided with gloves and masks while only $20 \%$ were provided with other special equipment like leg protectors, boots and aprons. Only $40 \%$ of the hospitals color coded the waste for disposal while no such practices were observed in the remaining $60 \%$ of the hospitals.

The facilities available for the waste disposal in different hospitals included burial, burning and incineration. Burial of the waste was conducted in $86.67 \%$ of the hospitals, while in $13.3 \%$ it was burned in open air. Incineration was carried out in $33.3 \%$ of the 


\begin{tabular}{|c|c|c|c|}
\hline \multirow{7}{*}{$\begin{array}{c}\text { Waste } \\
\text { management } \\
\text { team } \\
\text { members }\end{array}$} & & $\begin{array}{c}\text { No. of } \\
\text { hospitals }\end{array}$ & \%age \\
\hline & $0-7$ & 4 & 26.66 \\
\hline & $8-14$ & 2 & 13.33 \\
\hline & $15-21$ & 5 & 33.33 \\
\hline & $22-28$ & 1 & 6.66 \\
\hline & $29-55$ & 3 & 20 \\
\hline & Total & 15 & 100 \\
\hline \multirow{4}{*}{$\begin{array}{l}\text { Frequency of } \\
\text { revision of } \\
\text { WM plan }\end{array}$} & $\begin{array}{l}\text { Twice a } \\
\text { month }\end{array}$ & 1 & 6.66 \\
\hline & Monthly & 8 & 53.33 \\
\hline & Yearly & 6 & 40 \\
\hline & Total & 15 & 100 \\
\hline \multirow{4}{*}{$\begin{array}{l}\text { Frequency of } \\
\text { incineration }\end{array}$} & Daily & 9 & 60 \\
\hline & Twice weekly & 3 & 20 \\
\hline & Thrice weekly & 3 & 20 \\
\hline & Total & 15 & 100 \\
\hline
\end{tabular}

hospitals but no proper facility for disposal of radioactive waste was present. $33.34 \%$ of the hospitals returned the pharmaceutical waste to its suppliers while $66.67 \%$ of the hospitals did not.

In $60 \%$ of the health care institutes, the janitors and sanitary staff were immunized against common communicable diseases, while in 40\%, they were not. A Central Storage Facility was present in $53.34 \%$ of the hospitals.

In $60 \%$ of the health care enterprises, the head of every department was aware of the activities of the waste management team but daily monitoring by the WMO of the waste management plan was carried out only in $40 \%$ of the cases

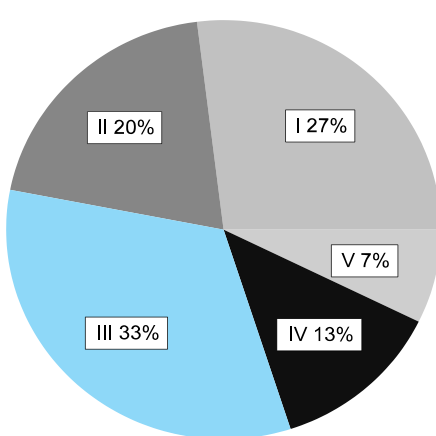

Sharp \& General waste

Infectious, Sharps \& general waste

Infectious, Sharps, Pathological \& General waste

Infectious, Sharps, Pathological, Pharmaceutical \& General waste

Infectious, Sharps, Pathological, Radioactive \& General waste

\section{Fig-1. Various types of wastes produced at the} hospitals studied

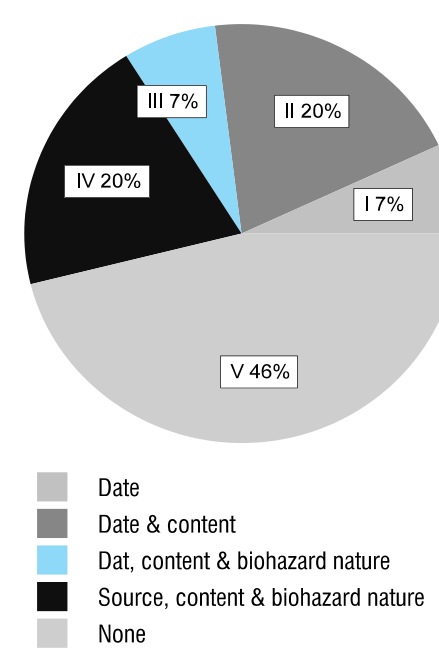

Fig-2. Labeling of containers/bags at the hospitals studied

\section{DISCUSSION}

Hospital waste management is a significant environmental and social obligation, and hence requires a proper plan. The hospital waste management plans are devised to incorporate a standard protocol for effective management of waste disposal. The study examined and analyzed the existing health care management status of the hospitals in Peshawar, KPK. 


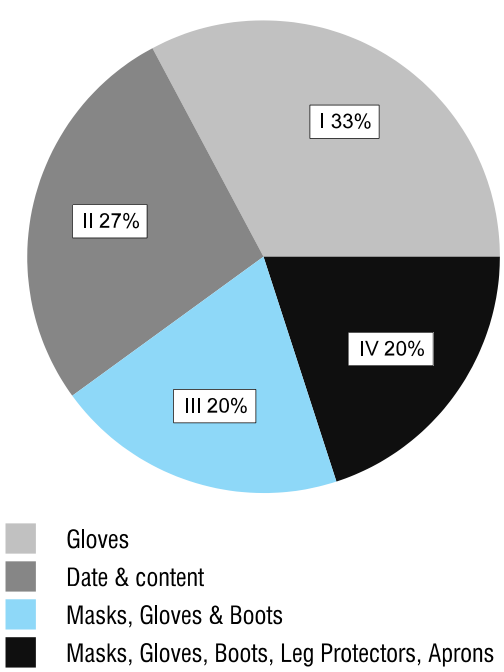

Fig-3. Personal protective equipments of staff at the hospitals studied

Regarding awareness, in our study doctors working in the hospitals were fully aware of the importance of hospital waste generation and its management, together with their responsibilities, while the lower staff including the janitors only possessed hearsay information. They lacked proper training though they were given some basic training in $73.3 \%$ of hospital. They were also unaware of the potential hazards to the environment. In $40 \%$ of the health care facilities, staff members were briefed about their duties and the hazards of their negligence only verbally.

In contrast, a study in Bangladesh reviewed lack of awareness and knowledge among the staff about hospital waste, its management and consequences to human health and the environment. 14 Another study in Dhaka city reported that there is also lack of awareness and willingness at health policy and law levels regarding proper management of medical waste $^{15}$.

Before taking responsibility of waste management, awareness of the potential hazards caused by improper disposal is important. In our study concerning HWM, it was found that $66.7 \%$ of the officials thought that safe and secure waste disposal along with its proper segregation is an important issue. A similar study in America showed that majority of the officials, not only considered HWM an important issue, but also aimed at reducing $67 \%$ of the waste by switching to less waste producing products ${ }^{16}$.

On the contrary, a study in Karnatika, India, suggested that for effectively accomplishing individual role in hospital waste disposal, proper training in separate training modules at each level should be targeted ${ }^{17}$.

Our study showed that the average waste generation in hospitals of Peshawar was 0.5-1 kg/bed/day, Compared to India: $1-2 \mathrm{~kg} / \mathrm{bed} /$ day, Nepal: 0.5 $\mathrm{kg} / \mathrm{bed} /$ day and in Bangladesh: 0.8-1.67 kg/bed/day.

In Pakistan, a study conducted by Mahmood-urRahman at Rawalpindi General Hospital, showed that average waste generation rate is $1.35 \mathrm{~kg} / \mathrm{bed} /$ day with maximum waste generation in surgical unit. Another study conducted at Distt. Hospital, Kusur, by Khaliq revealed that the average waste generation is 2.5 $\mathrm{kg} /$ patient/day, while risk waste generation was 0.5 $\mathrm{kg} /$ patient/day ${ }^{18}$.

Most of the waste generated was non risk waste in our study, making it $66.7 \%$ of the total waste. The rate of hospital waste generation in USA was reported higher as compared to our study i.e. 5.9 to $10.4 \mathrm{~kg} / \mathrm{bed} / \mathrm{day}$, whereas in the Western Europe it was $3-6 \mathrm{~kg} / \mathrm{bed} /$ day. In a under developed country in a rural hospitals, in sub-Saharan Africa the daily production of solid waste ranged between 0.3 to $1.5 \mathrm{~kg} / \mathrm{bed} /$ day $^{19,20}$.

In Peshawar, It was also found that $93.34 \%$ of the hospitals do separate the waste into risk and non-risk types and these are segregated at the point of generation in most of the cases. Such a practice is of vital importance as if not done, it can lead to various disease conditions. Studies from developed countries showed that majority of the hospitals segregated their 
waste into infectious and non-infectious categories $^{21,22}$. Hospitals from developed countries does not quantify and segregate medical waste into infectious waste and non-infectious waste as was reported in an African hospital ${ }^{23}$.

Still, $46.67 \%$ of the hospitals were not labeling/color coding the waste which is essential for their proper disposal according to their source, nature and level of biohazard. The rest of $53.3 \%$ labeled the waste according to date/content or source etc. On the contrary, a study performed in America showed that most of the hospitals used color coding to segregate their wastes. They also used purpose designed containers especially for sharps leading to a low percentage of disposal related injuries i.e. only $20 \%$ at a New York teaching hospital ${ }^{24,25}$.

Our study reported that the facilities available for the waste disposal in different hospitals included burial, burning and incineration etc. burial of the waste was conducted $86.67 \%$ of the hospitals while in the rest it was burned. For risk waste, incineration was carried out in $33.3 \%$ of the hospitals but no proper facility for disposal of radioactive waste was present.

Studies in UK showed that the major means of disposal of waste there is landfill, with about 4000 sites for the purpose. Incineration is the second most important means with $14.5 \%$ of the waste disposed of in this manner, discouraged now owing to the potential adverse effects to the environment ${ }^{26}$. A similar study in Kathmandu, Nepal showed that $62 \%$ of the hospitals practiced combustion of waste, either by incineration or open burning ${ }^{27}$. In the hospitals of Peshawar, KPK, even though incineration is carried out, apart from a few most hospitals make use of make-shift incinerators that operate at lower temperatures releasing noxious gases into the environment making it a great environmental hazard.

This is in contrast to the fact that $80 \%$ of the health personnel were aware of the hospital waste and its management and $66.67 \%$ of these considered the segregation and safe disposal of waste a proper issue. The problem lies with compliance of health care guidelines. This may be due to additional financial and work burden these procedures pose to the health care enterprises. A study in India also shows that $98 \%$ of the health care institutes with proper permits do not possess proper waste treatment schemes ${ }^{28}$.

Even though the "Hospital waste management rules 2005" notified by the Federal Government of Pakistan under the Environmental Protection act 1997 clearly state that a proper storage facility should be present in the hospitals and the WMO should oversee the correct use of such a facility and ensure correct method of transportation of waste, it was found that daily monitoring by the WMO was done in only $40 \%$ of the cases. Also, a central storage facility was found in only $53 \%$ of the hospitals and recording of waste transportation was done in only $47 \%$ of the cases ${ }^{29,30}$.

While comparing the study "Hospital waste management in the hospitals of Peshawar, KPK", with other studies conducted in various cities of different provinces in Pakistan, the overall situation is not very much different regarding waste generation, prevailing practices of hospital waste disposal, attitude of sanitary workers use of personal protective devices while handling the hospital waste, and vaccination of sanitary workers against Hep B.

Copyright@ 05 Aug, 2013.

\section{REFERENCES}

1. Hospital waste management. Parn, Pakistan. Antimicrobial resistance network. http://www.parn.org.pk/ index_files/HOSPITALWASTE.html

2. Shahida Rasheed, Saira Iqbal, Lubna A. Baig, Kehkashan Mufti. Hospital Waste Management in the Teaching Hospitals of Karachi. (JPJMA 55:192; 2005). wwwjpma.org.pk/fullarticletext. php? article_id $==737$ 
3. Hospital Waste Factsheet Environmental Pollution Unit, WWF- Pakistan, http:// www. wwfpak. org/factsheetshwf php

4. Waste Care Corporation. Trash Compactors and Waste Disposal. (Reference Article C9-I-CS-020311) Available at: www.wastecare.com > Sitemap > Compactors [cited: June 2012].

5. A. Priiss, W.K. Townsend. Teacher's Guide: Management of Wastes from Health-Care Activities. WHO publications: hospitals. Geneva, WHO, 1998. WHO/EOS/98.6 https://apps.who.int/dsa/cat98/ hosp8.htm

6. Patience Aseweh Abor, Anton Bouwer, (2008) "Medical waste management practices in a Southern African hospital". International Journal of Health Care QuaHty Assurance 2008; 21(4): pp.356-364.

7. Manzurul Hassan, Shafml A Ahmed, K Anisur Rahman, Tarit K Biswas. Pattern of medical waste management: existing scenario in Dhaka City, Bangladesh MBMC Public Health 2008, 8:36 doi: 10.1186/1471-2458-8-36.

8. Department of Tetarimahi. Guidelines for the Safe Handling of Cyto-toxic Drugs and Related Waste. Occupational Safety and Health Information Series. www.osh.dol.govt.nz/order/catalogue/pdf/cytodrug.p $\mathrm{df}$

9. Royal Children Hospital Melbourne. Royal Children's Hospital Waste Management Plan August 2005. Available at: www.rch.org.au/emplibrary/infection.../ RCHWastemagtPlan.pdf.

10. Why is Recycling So Important? www.earthsfriends.com/why-recycling-important A Horvath Management of Waste Disposal in Medical Institutions. 1991 www.ncbi.nlm.nih.gov/pubmed/ 2027662.

11. JP Hageman. Handling, Storage, Treatment, and Disposal of Mixed Wastes at - NCBI. 2002 www.ncbi.nlm.nih.gov/pubmed/12003031.

12. Health-Care Waste Management Planning. www.who.int/entity/water...health/medicalwaste/034t 0057.pdf.
13. Survey Report, Executive Summary. Hospital Waste Management in Dhaka City - Prism Bangladesh. Available at: www.prismbd.org/Hospital\%20waste\%20 management\%202005-05-2 Cited [June 6, 2012].

14. Pattern of Medical Waste Management: Existing Scenario in Dhaka City, Bangladesh. MBMC Public Health 2008, 8:36 doi: 10.1186/1471-2458-8-36.

15. Legacy Health System. A Model Waste Prevention Program, May 4 994. A Model Waste Prevention Program, www.p2pays.org/ref/01/00900.pdf.

16. The World Bank. Health Care Waste Management in India, Lessons From Experience. Bekir Onursal, the Publisher, the World Bank, October 2003 www.worldbank.org/.../1705736.../HCWMText.pdf.

17. Mazhar ul Khaliq. Waste Management in Health Care Sector. www.scribd.com/doc/.../Waste-Managementin-Health-Care-Sector

18. Mujahid Wazir, Iqbal Ahmad Khan, Shujaat Hussain, Ayaz Hussain Qureshi, Shaukat Mahmood Qureshi, Muhammad Ashraf Chaudhry. Hospital waste management in a tertiary care Army hospital. Pak Armed Forces Med J Dec 2005;55(4):349-54.

19. Khairun nessa, M.A Quaiyum, Barkat-e-Khuda. Waste management in healthcare facilities: a review. [WP144, 2001]. ICDDR,B: Centre for Health and Population Research .Mohakhali, Dhaka 1212. Bangladesh. ICDDR,B Working Paper No. 144 www.icddrb.org/component/search.../3163. healthcare-wastes - Bangladesh

20. United Nations Environment Programme. Strategy on Biomedical (Healthcare) Waste Management. Fonner Yugoslav Republic of Macedonia, Skopje, January 2008. HCWM Strategy Macedonia draft final DLkl 160508x-I. Available at: www. archive, basel int/centers/projactiv/tctf_projects/015-7.pdf.

21. Ngwuluka Ndidi, Ochekpe Nelson, Odumosu Patricia and John Sunday. Waste Management In Healthcare Establishments Within Jos Metropolis, Nigeria. African Jour of Env Sci \& Techn Vol. 3 (12), pp. 459465. Dec, 2009. Available at http://www.academic journals.org/AJEST. ISSN 1991-637X,2009.

22. Patience Aseweh Abor, Anton Bouwer, (2008) "Medical 
waste management practices in a Southern African hospital". International Journal of Health Care Quality Assurance, Vol.21 Iss: 4, pp.356-364.

23. S. V. Manyele, T. J. Lyasenga. Factors affecting medical waste management in low- level health facilities in Tanzania. African Journal of Environmental Science and Technology Vol. 4(5), pp. 304-318, May 2010. ISSN 1991-637X @ 2010 Academic Journals. Available online at: w/vw.ajol.info/index.php/ajest/ article/view/56369/44804.

24. Shalini Sharma, S.V.S.Chauhan. Assessment of biomedical waste management in three apex Government hospitals of Agra. Jour of Env Biology March 2008, 29(2) 159-162 (2008)Triveni Enterprises, Lucknow (India) wV|W.jeb.co.in/journaljssues/200803 mar08/paper_06.pdf.

25. Ka Brown. Economic Evaluation of PVC Waste Management. 2000; ec.europa.eu/emnronment/ waste/sttidies/pvc/economiceval.pdf
26. Nepal Forum of Environmental Journalists. Public Information and Awareness-Raising on Unintentionally Produced POPs from Medical Waste, May 2006. Kathmandu, Nepal. www.ipen.org/.../..

27. Dr Geeta Mehta. Infection Control and Health Care Waste Management in the Kingdom of Bhutan. A Mission Report, World Health Organisation, Regional Office for South East Asia (SEARO). May 2005.

28. www. Whobhutan. Org/.. ./Healthlnformationlnfect oncontro 1. Pdf

29. Govt. of Pakistan, Ministry of Environment. Brief on Environment Policy and Legal Framework Islamabad, 3rd August, 2005, notification, www.environment.gov.pk/...

30. Govt. of Pakistan, Ministry of Environment. "Hospital Waste Management Rules 2005, under the Environmental Protection act, 1997 brief on Environment Policy and Legal Framework, www. Environment.Gov. Pk/.../

\section{AUTHOR(S):}

1. DR. RAHEELAH AMIN

FCPS (Community Medicine)

Assistant Professor,

Department of Community Medicine

Khyber Girls Medical College, Peshawar

2. DR. RUBINA GUL

Assistant professor

Khyber Medical College, Peshawar

3. MISS AMINA MEHRAB

Final Year student

Khyber Medical College, Peshawar
Correspondence Address:

Dr. Raheelah Amin

FCPS (Community Medicine)

Assistant Professor,

Department of Community Medicine

Khyber Girls Medical College, Peshawar

raheelahamin@yahoo.com 